\title{
Transcription Elongation Factor SPT6
}

National Cancer Institute

\section{Source}

National Cancer Institute. Transcription Elongation Factor SPT6. NCI Thesaurus. Code C17419.

Transcription elongation factor SPT6 (1726 aa, 199 kDa) is encoded by the human SUPT6H gene. This protein is involved in transcriptional regulation. 